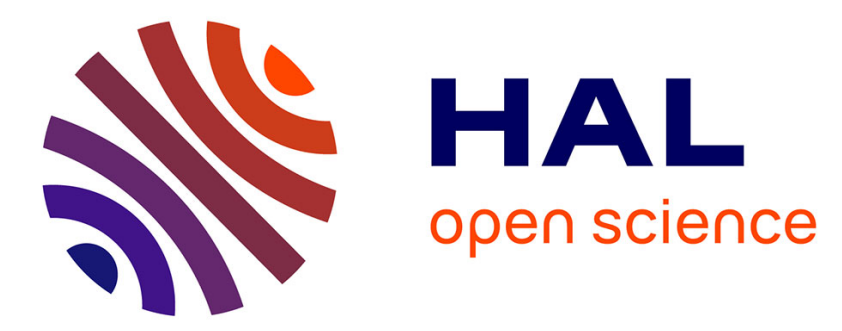

\title{
Synthesis, structural characterization and transformation of an eight-electron superatomic alloy, [Au@Ag-19S2P $(\mathrm{OPr})(2)(12)]$
}

Yan-Ru Lin, Pilli V. V. N. Kishore, Jian-Hong Liao, Samia Kahlal, Yu-Chiao Liu, Ming-Hsi Chiang, Jean-Yves Saillard, C. W. Liu

\section{To cite this version:}

Yan-Ru Lin, Pilli V. V. N. Kishore, Jian-Hong Liao, Samia Kahlal, Yu-Chiao Liu, et al.. Synthesis, structural characterization and transformation of an eight-electron superatomic alloy, [Au@Ag19S2P(OPr)(2)(12)]. Nanoscale, 2018, 10 (15), pp.6855-6860. 10.1039/c8nr00172c . hal-01807074

HAL Id: hal-01807074

https://hal-univ-rennes1.archives-ouvertes.fr/hal-01807074

Submitted on 13 Jul 2018

HAL is a multi-disciplinary open access archive for the deposit and dissemination of scientific research documents, whether they are published or not. The documents may come from teaching and research institutions in France or abroad, or from public or private research centers.
L'archive ouverte pluridisciplinaire HAL, est destinée au dépôt et à la diffusion de documents scientifiques de niveau recherche, publiés ou non, émanant des établissements d'enseignement et de recherche français ou étrangers, des laboratoires publics ou privés. 


\title{
Synthesis, Structural Characterization and Transformation of an Eight-Electron Superatomic Alloy, [Au@ $\left.\mathrm{Ag}_{19}\left\{\mathrm{~S}_{2} \mathrm{P}(\mathrm{OPr})_{2}\right\}_{12}\right]$
}

Yan-Ru Lin, ${ }^{[a]}$ Pilli V. V. N. Kishore, ${ }^{[a, d]}$ Jian-Hong Liao, ${ }^{[a]}$ Samia Kahlal, ${ }^{[b]}$ Yu-Chiao Liu, ${ }^{[c]}$ Ming-Hsi Chiang, ${ }^{[c]}$ Jean-Yves Saillard, ${ }^{*[b]}$ and C. W. Liu* ${ }^{[a]}$

\begin{abstract}
Controlling the metal nanoclusters with atomic precision is highly difficult and further studies on their transformation reactions are even more challenging. Herein we report the controlled formation of silver alloy nanocluster $\left[\mathrm{AuAg}_{19}\left\{\mathrm{~S}_{2} \mathrm{P}\left(\mathrm{O}^{\mathrm{n}} \mathrm{Pr}\right)_{2}\right\}_{12}\right]$ (1) from an $\mathrm{Ag}_{20}$ template via a galvanic exchange route. X-ray structural analysis reveals that the

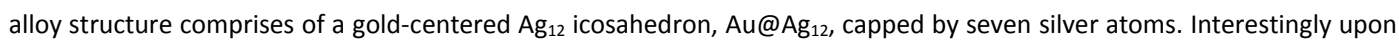
reacting with one equiv. of silver(I) salt, (1) can transform into a higher nuclearity nanocluster, $\left[\mathrm{Au} @ \mathrm{Ag}_{20}\left\{\mathrm{~S}_{2} \mathrm{P}\left(\mathrm{O}^{\mathrm{n}} \mathrm{Pr}\right)_{2}\right\}_{12}\right]^{+}$ (2). The conversion process is studied via ESI mass spectrometry and ${ }^{31} \mathrm{P} N M R$ spectroscopy. This kind of size-structural transformation at the single atom level is quite remarkable. Further the compositions of all the doped nanoclusters $(\mathbf{1}, \mathbf{2})$ were fully characterized with ESI-MS and EDS. The blue shift depicted in the UV-visible and emission spectra for the doped nanoclusters $(\mathbf{1}, \mathbf{2})$ comparing with the precursor, $\mathrm{Ag}_{20}$, demonstrates that the doping atoms have significant effects on the electronic structures.
\end{abstract}

\section{Introduction}

During the last decade an increasing interest of research topics was focused on atomically precise nanoclusters (NCs) and alloys. The precise atomic structure is fundamentally important in exploring structure-property relationships. In fact atomically precise, noble metal NCs act as a bridge between metal atoms and nanoparticles. ${ }^{1}$ Over the past two decades Au nanoclusters have been actively pursued owing to their unusual stabilities. ${ }^{2}$ Very recently the research has been extended to silver following the breakthrough discovery of $\mathrm{Ag}_{44}$ by Bigioni and Zheng. ${ }^{3} \mathrm{~A}$ series of $\mathrm{Ag}$ nanoclusters $\mathrm{Ag}_{14}{ }^{4}$ $\mathrm{Ag}_{16},{ }^{5} \mathrm{Ag}_{20},{ }^{6} \mathrm{Ag}_{21}{ }^{7} \mathrm{Ag}_{25},{ }^{8} \mathrm{Ag}_{29},{ }^{9} \mathrm{Ag}_{32},{ }^{5} \mathrm{Ag}_{34},{ }^{10} \mathrm{Ag}_{50}{ }^{11}, \mathrm{Ag}_{136}{ }^{12}$ and $\mathrm{Ag}_{374,}{ }^{12}$ have been synthesized and structurally characterized. In the subsequent years, researches on the alloy nanoclusters have gained momentum since alloys have witnessed unique advantages over the homometallic counterparts ranging from enhanced stability, catalytic activity, reactivity and optical properties. ${ }^{13}$ In general the alloy clusters are synthesized by either one-pot co-reduction reactions with mixed metal precursors or post-synthetic reactions of a NC with the specific metal precursor. ${ }^{14}$ Recently Pradeep and coworkers reported an inter-cluster reaction method for obtaining alloy nanoclusters. ${ }^{15}$ To date, a number of atom-precise Au based alloy nanoclusters have been reported. Especially doping on $\mathrm{Au}_{25}(\mathrm{SR})_{18}$ was extensively studied with metals such as $\mathrm{Cu}^{14}$ $\mathrm{Pd},{ }^{16} \mathrm{Pt}^{16} \mathrm{Ag},{ }^{14,17} \mathrm{Cd}^{18}$ and $\mathrm{Hg}^{19}$. In contrast, silver-rich alloy nanoclusters are comparatively scarce. Like $\mathrm{Au}, \mathrm{Ag}$ can also mix with foreign metals such as $\mathrm{Pd}, \mathrm{Pt}, \mathrm{Ni}$, and $\mathrm{Cu}$ at the nanoscale to produce alloy clusters $\left(\mathrm{Ag}_{4} \mathrm{M}_{2},{ }^{20} \mathrm{M}=\mathrm{Ni}, \mathrm{Pt} ; \mathrm{Ag}_{5} \mathrm{Pd}_{4} ;{ }^{21} \mathrm{MAg}_{24}\right.$, $\mathrm{M}=\mathrm{Pt}, \mathrm{Pd}^{22}$ and $\mathrm{Ag}_{28} \mathrm{Cu}_{12}{ }^{23}$ ) with different compositions. In the past few years, reports of $\mathrm{Ag}-\mathrm{Au}$ nanoalloys were constantly expanding and their structure-property relationships have been well studied. Prominent examples include $\mathrm{Au}_{25-x} \mathrm{Agx},{ }^{24} \mathrm{Au}_{38-\mathrm{x}} \mathrm{Agx}^{25} \mathrm{Au}_{24} \mathrm{Ag}_{20}{ }^{26} \mathrm{Au}_{24} \mathrm{Ag}_{46}{ }^{27} \mathrm{Au}_{\mathrm{x}}$ $\mathrm{Ag}_{50-x},{ }^{11} \mathrm{Au}_{12} \mathrm{Ag}_{32},{ }^{3 \mathrm{~b}} \mathrm{Au}_{25} \mathrm{Ag}_{2}{ }^{28} \mathrm{Ag}_{28} \mathrm{Au}^{29} \mathrm{Au}_{12} \mathrm{Ag}_{13}{ }^{30}, \mathrm{Au}_{80} \mathrm{Ag}_{30}{ }^{31}$ $A u A_{24}{ }^{32}$ and $A u_{4} A_{1} g_{13}{ }^{33}$ Quite recently our group reported the first $A u @ A g_{20}$ alloy nanocluster passivated by selenium ligands. ${ }^{34}$

On the other hand the accessibility of nanoclusters with precise formula and structure makes it possible to investigate their transformations akin to organic ensembles in organic chemistry. However the structural transformations in nanochemistry are very least understood upon comparing to well-documented organic chemistry. Even though the history of nano-chemistry was still very young (two decades), some remarkable transformations of $\mathrm{Au}$ nanoclusters include $\mathrm{Au}_{25}$ to $\mathrm{Au}_{28},{ }^{35} \mathrm{Au}_{38}$ to $\mathrm{Au}_{36},{ }^{36}$ and $\mathrm{Au}_{144}$ to $\mathrm{Au}_{133},{ }^{37}$ were known. Bakr et al. has studied these transformations in silver nanoclusters by employing ligand exchange methods. ${ }^{38}$ Recently Zhu and coworkers reported a bimetallic $\mathrm{Pt}_{1} \mathrm{Ag}_{28}$ nanocluster that was obtained by etching $\mathrm{Pt}_{1} \mathrm{Ag}_{24}$ with thiol ligands. ${ }^{39}$ Further transformation of $\mathrm{Au}_{23-\mathrm{x}} \mathrm{Agx}$ to $\mathrm{Au}_{24}$-xAgx has also been reported. $^{40}$ 


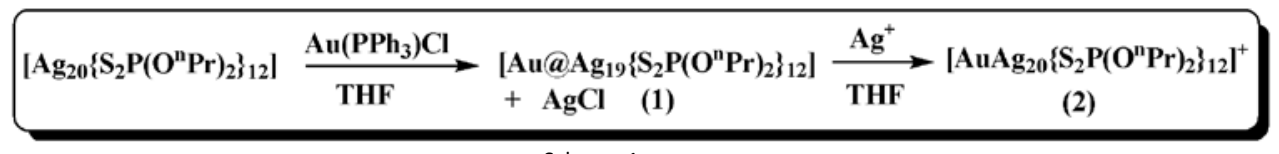

Scheme 1

Lately we developed a new approach in using dithiolate-type ligands in the preparation of two 8-electron superatomic silver $\mathrm{NCs},\left[\mathrm{Ag}_{21}\left\{\mathrm{~S}_{2} \mathrm{P}(\mathrm{OR})_{2}\right\}_{12}\right]^{+}$, and $\left.\left[\mathrm{Ag}_{20}\left\{\mathrm{~S}_{2} \mathrm{P}(\mathrm{OR})_{2}\right\}_{12}\right]\right]^{7,8}$ We also demonstrated the possibility of controlled reversible transformations of the $\mathrm{Ag}_{20}$ to $\mathrm{Ag}_{21} \mathrm{NCs}$ by adding either $\mathrm{Ag}^{\prime}$ or $\left[\mathrm{BH}_{4}\right]^{-}$to the precursors. Inspired by the aforementioned successful findings on silver alloy clusters and their structural transformations, we considered it will be of great interest to employ either $\mathrm{Ag}_{20}$ or $\mathrm{Ag}_{21} \mathrm{NCs}$ as potential templates in producing doped NCs by using galvanic exchange methods and further study the NCs reactivity towards transformations. Herein, we report a new alloy $\mathrm{Au}-\mathrm{Ag}$ nanocluster formulated as $\left[\mathrm{AuAg}_{20}\left\{\mathrm{~S}_{2} \mathrm{P}\left(\mathrm{O}^{\mathrm{n}} \mathrm{Pr}\right)_{2}\right\}_{12}\right]^{+}$(2) which is fabricated from $\left[\mathrm{AuAg}_{19}\left\{\mathrm{~S}_{2} \mathrm{P}\left(\mathrm{O}^{\mathrm{n}} \mathrm{Pr}\right)_{2}\right\}_{12}\right]$ (1) by reacting it with one equiv. of $\mathrm{Ag}^{\prime}$ salt. For the synthesis of the doped $\mathrm{NC} A u @ \mathrm{Ag}_{19}$ (1), a templated galvanic synthesis was adopted.

In a typical synthesis, $\left[\mathrm{Ag}_{20}\left\{\mathrm{~S}_{2} \mathrm{P}\left(\mathrm{O}^{\mathrm{n}} \mathrm{Pr}\right)_{2}\right\}_{12}\right]$ was firstly dissolved in tetrahydrofuran (THF), then $\mathrm{Au}\left(\mathrm{PPh}_{3}\right) \mathrm{Cl}$ was added instantaneously. The reaction was stirred at $-20^{\circ} \mathrm{C}$ for $2 \mathrm{~h}$. The solvents were removed under reduced pressure to obtain a dark red solid. The residue was thoroughly washed with a DCM/water mixture. The DCM layer was separated and dried under vacuum to yield $\left[\mathrm{AuAg}_{19}\left\{\mathrm{~S}_{2} \mathrm{P}\left(\mathrm{O}^{\mathrm{n}} \mathrm{Pr}\right)_{2}\right\}_{12}\right] \quad$ (1). $\left[\mathrm{AuAg}_{20}\left\{\mathrm{~S}_{2} \mathrm{P}\left(\mathrm{O}^{\mathrm{n}} \mathrm{Pr}\right)_{2}\right\}_{12}\right]^{+}$(2) was synthesized from (1) under similar conditions, except that $\mathrm{Au}\left(\mathrm{PPh}_{3}\right) \mathrm{Cl}$ was replaced by $\left[\mathrm{Ag}\left(\mathrm{CH}_{3} \mathrm{CN}\right)_{4}\right] \mathrm{PF}_{6}$ (Scheme 1).

\section{Results and Discussion}

To confirm the nanocluster formula of $\mathbf{1}$ and to probe the charge state of the cluster, we performed an electrospray ionization mass spectrometric analysis (ESI-MS). Firstly in the mass spectrum no residual peak corresponding to $\left[\mathrm{Ag}_{20}\left\{\mathrm{~S}_{2} \mathrm{P}\left(\mathrm{O}^{\mathrm{n}} \mathrm{Pr}\right)_{2}\right\}_{12}\right](\mathrm{m} / \mathrm{z} 4716.30)$ was observed indicating that the precursor was totally consumed. However we could not observe the expected species, $A u @ A_{19}$, a peak at $\mathrm{m} / \mathrm{z}$ 4805.37. Instead, in the positive ESI-MS spectrum of 1 a set of adduct peaks at $\mathrm{m} / \mathrm{z} 4913.23$ (calcd 4913.27) and 5001.33 (calcd 5001.34) corresponding to the molecular formulae $\left[\mathrm{AuAg}_{20}\left\{\mathrm{~S}_{2} \mathrm{P}\left(\mathrm{O}^{\mathrm{n}} \mathrm{Pr}\right)_{2}\right\}_{12}\right]^{+}$and $\quad\left[\mathrm{Au}_{2} \mathrm{Ag}_{19}\left\{\mathrm{~S}_{2} \mathrm{P}\left(\mathrm{O}^{\mathrm{n}} \mathrm{Pr}\right)_{2}\right\}_{12}\right]^{+}$, respectively, were identified (Figure 1 ). Furthermore, an additional peak ( $\mathrm{m} / \mathrm{z} 2177.19)$ in 1 at the lower mass region attributed to $\left[\mathrm{Ag}_{8} \mathrm{Cl}\left\{\mathrm{S}_{2} \mathrm{P}\left(\mathrm{O}^{\mathrm{n}} \mathrm{Pr}\right)_{2}\right\}_{6}\right]^{+}$has also been observed. The molecular formula assignments for the unexpected products were further confirmed by their experimental isotopic distribution patterns that match closely with the simulated patterns. Actually, the ESI-MS data clearly indicate that there has been a clear replacement of $\mathrm{Ag}$ by $\mathrm{Au}$ in the $\left[\mathrm{Ag}_{20}\right]$ precursor (Scheme 1). Furthermore, the results also reveal that the total number of metal atoms in the identified $\left[\mathrm{AuAg}_{20}\left\{\mathrm{~S}_{2} \mathrm{P}\left(\mathrm{O}^{\mathrm{n} P r}\right)_{2}\right\}_{12}\right]^{+}$and $\left[\mathrm{Au}_{2} \mathrm{Ag}_{19}\left\{\mathrm{~S}_{2} \mathrm{P}\left(\mathrm{O}^{\mathrm{n}} \mathrm{Pr}\right)_{2}\right\}_{12}\right]^{+}$species were not preserved at 20 but increased to 21 . We hypothesized that $\mathrm{Au} @ \mathrm{Ag}_{19}$ might have relatively deprived protecting capability for the metal core due to a limited structural stability embarked on its NC surface in such harsh gas phase conditions. Therefore, only the alloy NCs ( $\mathrm{AuAg}_{20}$ and $\mathrm{Au}_{2} \mathrm{Ag}_{19}$ ) with good stability could finally survive. This is not very surprising since there are instances where NCs are transformed into other species of different stabilities in gas phase conditions. ${ }^{6}$ Nevertheless the structure of $A u @ \mathrm{Ag}_{19}$ has been confirmed by single crystal X-ray diffraction analysis (vide infra). The ESI-mass results of $\mathbf{1}$ particularly spurred our

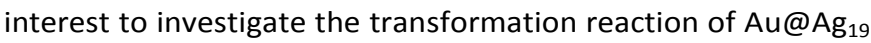
to $A u A g_{20}$. So the reaction of $\left[A u @ A g_{19}\left\{S_{2} P\left(O^{n} P r\right)_{2}\right\}_{12}\right]$ with one equiv. of $\mathrm{Ag}\left(\mathrm{CH}_{3} \mathrm{CN}\right)_{4} \mathrm{PF}_{6}$ in THF was processed. We observed an immediate color change in the reaction. ESI-MS of the purified product gave rise to the same intense peak at $\mathrm{m} / \mathrm{z} \sim$ 4913.23 attributable to $\left[\mathrm{Au} @ \mathrm{Ag}_{20}\left\{\mathrm{~S}_{2} \mathrm{P}\left(\mathrm{O}^{\mathrm{n}} \mathrm{Pr}\right)_{2}\right\}_{12}\right]^{+}$(2) (Figure 2). The ESI-MS indicates the purity and the atomic monodispersity of the as-synthesized product. Experimental data matched well with the simulation (see inset) for the assigned molecular formula. Furthermore, in the ${ }^{31} \mathrm{P}$ NMR spectrum, $\left[\mathrm{Au} @ \mathrm{Ag}_{20}\left\{\mathrm{~S}_{2} \mathrm{P}\left(\mathrm{O}^{\mathrm{n}} \mathrm{Pr}\right)_{2}\right\}_{12}\right]^{+}$exhibits a sharp peak at 103.75 ppm (

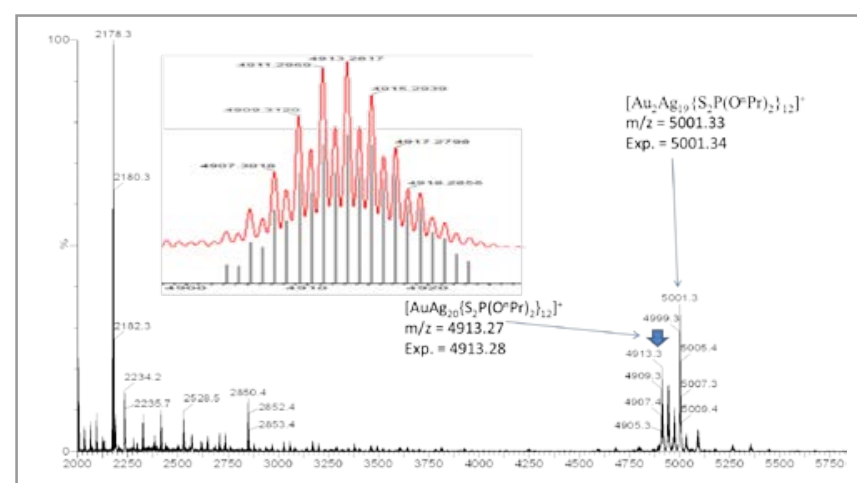

Figure 1. Positive ESI-MS spectrum of 1. The inset shows the experimental and theoretical isotopic pattern

TESI figure S1), much different from that in [Au@Ag $\left.{ }_{19}\left\{\mathrm{~S}_{2} \mathrm{P}\left(\mathrm{O}^{\mathrm{n}} \mathrm{Pr}\right)_{2}\right\}_{12}\right]$ which resonates at comparatively downfield regions (105.6 ppm) (Figure S2 tESI). We also identified a $\mathrm{PF}_{6}$ anion in the ${ }^{31} \mathrm{P} N \mathrm{NMR}$ spectrum that additionally confirms that $\mathbf{2}$ is a positively charged NC. The 


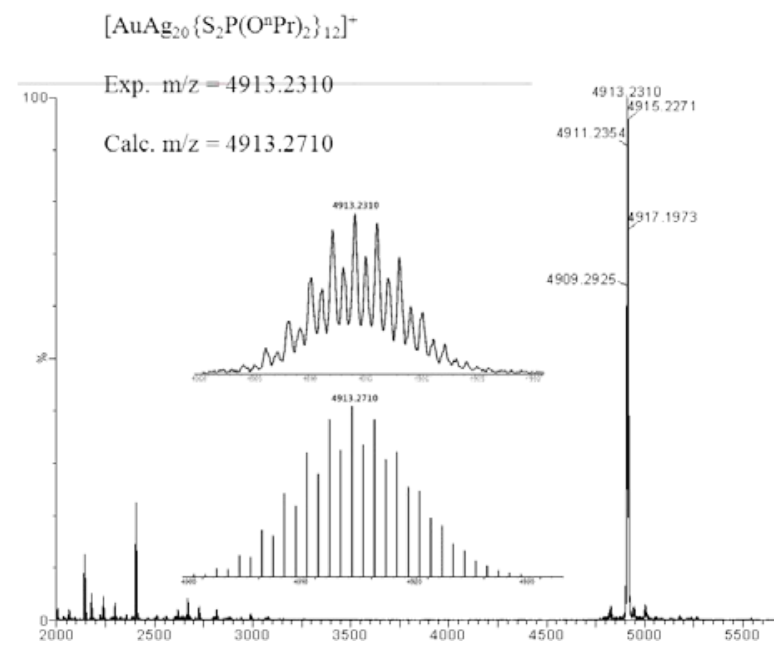

Figure 2. Positive ESI-MS spectrum of 2 . The inset shows the experimental and theoretical isotopic patterns.

single sharp signal in ${ }^{31} \mathrm{P}$ NMR spectra could be possibly due to fast exchange process of chemically nonequivalent dtp ligands, much faster than the NMR time scale. Though the above observations clearly demonstrates the transformation of $A u @ A_{19}$ to $A u @ A_{20}$, we were unfortunately unable to grow single crystals of $\left[\mathrm{Au} @ \mathrm{Ag}_{20}\left\{\mathrm{~S}_{2} \mathrm{P}\left(\mathrm{O}^{\mathrm{n}} \mathrm{Pr}\right)_{2}\right\}_{12}\right]^{+}$suitable for $\mathrm{X}$ ray diffraction studies. It should be mentioned that a related $\mathrm{Au} @ \mathrm{Ag}_{20}$ cluster has been recently reported by us; namely $\left[\mathrm{AuAg}_{20}\left\{\mathrm{Se}_{2} \mathrm{P}(\mathrm{OEt})_{2}\right\}_{12}\right]^{+}$, which exhibits an $\mathrm{Au} @ \mathrm{Ag}_{12}$ centered icosahedron surrounded by 12 diselenophosphate (dsep) ligands and $8 \mathrm{Ag}$ capping atoms in a cubic arrangement. ${ }^{34}$ So herein for the mechanistic approach, we assume that, under galvanic reduction conditions, $\mathrm{Ag}_{20}$ reduces $\mathrm{Au}^{\prime}$ to $\mathrm{Au}$ which at the same time gets into the icosahedral framework to replace the central $\mathrm{Ag}$ atom which is likely to be subsequently integrated on the cluster surface as an $\mathrm{Ag}^{\prime}$ capping atom, leading to the monocationic species of higher nuclearity $\left[\mathrm{AuAg}_{20}\left\{\mathrm{~S}_{2} \mathrm{P}\left(\mathrm{O}^{\mathrm{n}} \mathrm{Pr}\right)_{2}\right\}_{12}\right]^{+}$. We assume that the incorporation of the exuded $\mathrm{Ag}^{+}$atom onto the $\mathrm{NC}$ surface is related to structural stability and shape flexibility factors associated with the NC outer shell, and not to the stable 8-electron superatomic core, since both $\left[\mathrm{AuAg}_{19}\left\{\mathrm{~S}_{2} \mathrm{P}\left(\mathrm{O}^{\mathrm{n}} \mathrm{Pr}\right)_{2}\right\}_{12}\right]$ and $\left[\mathrm{AuAg}_{20}\left\{\mathrm{~S}_{2} \mathrm{P}\left(\mathrm{O}^{\mathrm{n} P r}\right)_{2}\right\}_{12}\right]^{+}$have the same $\left[\mathrm{Ag}_{13}\right]^{5+}$ core. It is worthy to mention that the $\left[\mathrm{Au}_{2} \mathrm{Ag}_{19}\left\{\mathrm{~S}_{2} \mathrm{P}\left(\mathrm{O}^{\mathrm{n}} \mathrm{Pr}\right)_{2}\right\}_{12}\right]^{+} \mathrm{NC}$ identified in the ESI-MS of 1 has also an 8-electron count. An important conclusion that we can draw from here is the total atom number in the NC is altered to 21 , further confirming that structural stability (with 21 residual atoms) is the fundamental driving factor for the transformations. Since these reactions are instantaneous, it is not possible to identify the intermediates. Nevertheless in order to confirm our mechanistic assumption we synthesized yet another alloys $\left(A u @ \mathrm{Ag}_{19}\right)$ derived from isobutyl and isopropyl groups. The ESI-MS of the synthesized products revealed that $A u @ \mathrm{Ag}_{19}$ has been transformed into $A u @ \mathrm{Ag}_{20}$ further confirming structural stability is the solo driving force (Figure S3). Interestingly this kind of cluster transformation phenomenon at a single atom level has not been observed in either $\mathrm{Ag}$ or $\mathrm{Au}$ doped-NCs. Though there are some reports, most of them come from either ligand exchange methods or etching methods whose mechanisms are not very well understood. ${ }^{39-40}$ Indeed our experiments have shown fairly detailed mechanistic aspects of the transformation at the single atom level. However, there is still a lack in our understanding of the reasons for this structural transformation particularly in the interplay of energetic and kinetic factors.

The compositional and structural assumption from mass spectrometry of 1 was further confirmed by single-crystal Xray analysis. The structural elucidation ${ }^{41}$ of 1 reveals a basic framework similar to that of previously reported $\mathrm{Ag}_{20} \mathrm{NCs}$. It is composed of a central $\mathrm{Au}$ atom surrounded by $12 \mathrm{Ag}$ atoms; these 13 atoms constitute the inner icosahedral core (Figure $3 b)$. The refinement to $\mathrm{Au}$ atom is only successful for the central position. However, the 12 icosahedral $\mathrm{Ag}$ atoms have $100 \%$ occupancy, confirming that Au selectively occupies the central position. The NC shell of $\mathbf{1}$ is composed of $12 \mathrm{dtp}$ ligands and 7 capping silver atoms, arranged on 7 of the 20 triangular faces of the $\mathrm{Ag}_{12}$ icosahedron (Figure $3 \mathrm{~b}$ ). Two capping silver atoms on any of the two adjacent triangular faces resemble a butterfly motif with the hinge positions defined by their common triangular edges. The Ag-Ag distances in the centered icosahedral core were found in the range of 2.871(12)-2.993(13) $\AA$ and are similar to the previously reported $\mathrm{Ag}_{20}$ 2.8605(5)-3.0111(5), ${ }^{6} \mathrm{Ag}_{21} 2.842-$ 2.998, ${ }^{7} \mathrm{Ag}_{25}$ 2.8209-2.9975, ${ }^{8}$ and $\mathrm{Au} @ \mathrm{Ag}_{24} 2.861-2.978 .{ }^{32}$ The

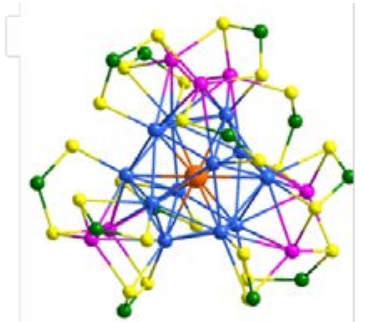

(a)

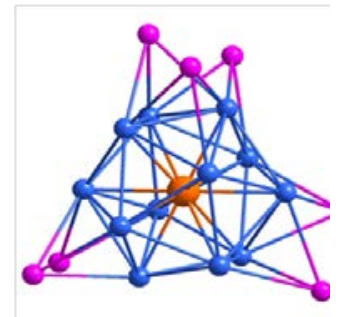

(b)
Figure 3: a) X-ray structure of the $\left[\mathrm{AuAg}_{19}\left\{\mathrm{~S}_{2} \mathrm{P}\left(\mathrm{O}^{\mathrm{n}} \mathrm{Pr}\right)_{2}\right\}_{12}\right]$ cluster with the $\mathrm{n}$ propoxy groups omitted for clarity. b) The $\mathrm{Au} @ \mathrm{Ag}_{19}$ core consisting of a centered icosahedron $\mathrm{Au} @ \mathrm{Ag}_{12}$ and seven capping $\mathrm{Ag}$ atoms (crimson). Color code: Au orange, Ag crimson and blue, $\mathrm{S}$ yellow, $\mathrm{P}$ green.

$\mathrm{Ag}_{\text {ico }}-\mathrm{Ag}_{\text {cap }}$ distances 2.9794(13)-3.1230(13) are found to be larger than the $\mathrm{Ag}_{\text {ico }}-\mathrm{Ag}_{\text {ico }}$ ones. The $\mathrm{Au}-\mathrm{Ag}$ icosahedron distances are in the order of 2.6945(8)-2.8136(10), closer to that in $\mathrm{Au} @ \mathrm{Ag}_{24}{ }^{32} 2.7443-2.7921$ and $\mathrm{Au} @ \mathrm{Ag}_{20},{ }^{34} 2.777(1) \AA$. Regarding the connectivity patterns of the dithiolates in $\mathbf{1}$, they are the same as those found in the precursor. The average bond lengths of $A g_{\text {ico }}-S$ and $A g_{\text {cap }}-S$ are $2.650 \AA$ and $2.520 \AA$, respectively, and the S $\cdots S$ bite distance is 3.419(4) Å. All these bond metric values are well matched with the $A_{20}$ parent $2.72 \AA, 2.51 \AA$ and 3.401(5) $\AA$. The seven $\mathrm{Ag}_{\text {cap }}$ atoms are held in nearly planar $\mathrm{AgS}_{3}$ coordination environment with 
the dtp ligands whereas it is $\mathrm{AgS}_{2}$ or AgS with respect to the $\mathrm{Ag}_{\text {ico }}$ atoms.

The composition of both alloy clusters $\mathbf{1}$ and $\mathbf{2}$ were analyzed by using energy-dispersive X-ray spectroscopy (EDS) (Figure S4, S5 ESI + ). The EDS results of $\mathbf{1}$ and $\mathbf{2}(\mathrm{Au} / \mathrm{Ag} / \mathrm{S} / \mathrm{P}$ atomic ratio to be 1.75: 35.21: 42.23: 20.81 for 1 and 1.74: 35.00: 42.32: 20.94 for 2 ) are in good agreement with the calculated values of the existing elements (table $2 \mathrm{ESI}+$ ). Further the XPS spectra of (1) reveals two characteristic peaks at binding energies $84.33 \mathrm{eV}$ and $367.78 \mathrm{eV}$ (Figure S6 ESI+), that corresponds to $\mathrm{Au}^{\circ}$ and $\mathrm{Ag}^{\prime}$ respectively. ${ }^{42,6}$ The UV-Vis spectrum of $\left[\mathrm{Ag}_{20}\left\{\mathrm{~S}_{2} \mathrm{P}\left(\mathrm{O}^{\mathrm{n}} \mathrm{Pr}\right)_{2}\right\}_{12}\right]$ displays two apparent peaks at $359 \mathrm{~nm}$ and $427 \mathrm{~nm}$, respectively (Figure 4 left side). However the spectra of $\mathbf{1}$ and $\mathbf{2}$ are significantly different from that of their $\left[\mathrm{Ag}_{20}\right]$ parent, suggesting there were profound effects of the incorporation of an $\mathrm{Au}$ heteroatom. In the doped $\mathrm{Ag}_{20}$ nanoclusters it was found that the $427 \mathrm{~nm}$ peak was blue-shifted to $420 \mathrm{~nm}(1,2)$ with apparent decrease in intensity. Further we also found that the absorption peak at $359 \mathrm{~nm}$ was red-shifted to $386 \mathrm{~nm}$ (1) and $375 \mathrm{~nm}$ (2) with increased intensity. This trend is different from the earlier reported $\mathrm{Au}_{12} \mathrm{Ag}_{32},{ }^{3 \mathrm{~b}} \mathrm{AuAg}_{24}{ }^{32}$ and $A u \mathrm{Ag}_{28}{ }^{29}$ wherein the clusters display only a blue shift. These results clearly demonstrate that the doping of gold atoms has a different influence towards optical behavior of 1 .

We have also studied the emission properties of $\mathbf{1}$ and 2. A comparison of the photoluminescence (PL) spectrum of $\mathrm{Ag}_{20}$, $\mathrm{AuAg}_{19}(\mathbf{1})$ and $\mathrm{AuAg}_{20}(\mathbf{2})$ is shown in Figure 4 (right side). The parent cluster $\mathrm{Ag}_{20}$ exhibits a characteristic emission band in the near-IR region at about $835 \mathrm{~nm}$ at $77 \mathrm{~K}$. The PLs of $\mathrm{AuAg}_{19}$ and $\mathrm{AuAg}_{20}$ show a clear blue shift from $835 \mathrm{~nm}$ to $782 \mathrm{~nm}$ and $745 \mathrm{~nm}$ with an increase in the luminescence intensity up to eight-fold. Interestingly the photoluminescence behavior is very similar to the recently reported $\mathrm{AuAg}_{20}{ }^{34} \mathrm{AuAg}_{24}{ }^{32}$ and $\mathrm{Ag}_{\mathrm{x}} \mathrm{Au}_{25-\mathrm{x}}{ }^{43}$ but the result deviates from $\mathrm{Au} @ \mathrm{Ag}_{28}$, which

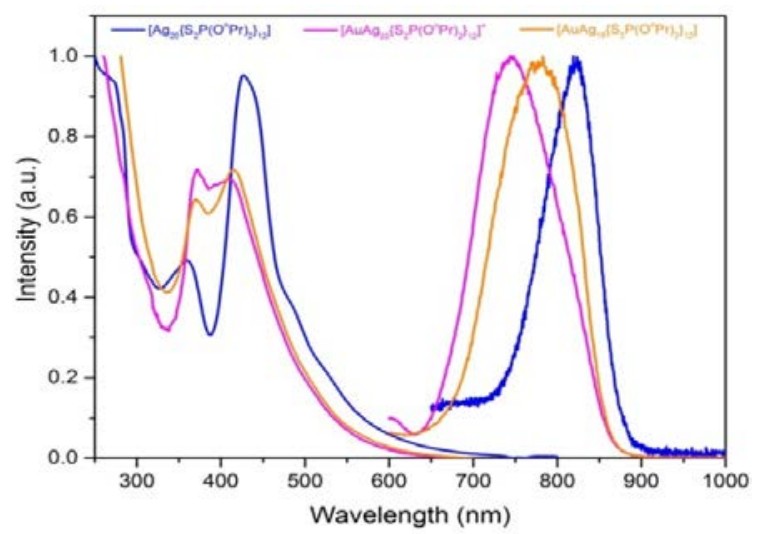

Figure 4: Normalized UV-Vis absorption (298K), and emission spectra (77K), of $\left[\mathrm{Ag}_{20}\left\{\mathrm{~S}_{2} \mathrm{P}\left(\mathrm{O}^{\mathrm{n}} \mathrm{Pr}\right)_{2}\right\}_{12}\right]$ (blue line), $\left[\mathrm{AuAg}_{19}\left\{\mathrm{~S}_{2} \mathrm{P}\left(\mathrm{O}^{\mathrm{n}} \mathrm{Pr}\right)_{2}\right\}_{12}\right]$ (1) (orange line) and $\left[\mathrm{AuAg}_{20}\left\{\mathrm{~S}_{2} \mathrm{P}\left(\mathrm{O}^{\mathrm{n}} \mathrm{Pr}\right)_{2}\right\}_{12}\right]^{+}$(red line) (2)

shows a red shift after doping.

DFT calculations ${ }^{44}$ have been carried out on simplified models (with dtp $=\mathrm{S}_{2} \mathrm{PH}_{2}$ ) of $\mathbf{1}, \mathbf{2}$ and their precursor $\left[\mathrm{Ag}_{20}\left\{\mathrm{~S}_{2} \mathrm{P}\left(\mathrm{O}^{\mathrm{n}} \mathrm{Pr}\right)_{2}\right\}_{12}\right]$, namely $\mathbf{1}^{\prime}, \mathbf{2}^{\prime}$ and $\left[\mathrm{Ag}_{20}\right]^{\prime}$, in order to understand their bonding and stability. Comparing the 20atom species $\left[\mathrm{Ag}_{20}\right]^{\prime}$ and $\mathbf{1}$, they have strongly related electronic structures. They are closed-shell superatoms with an 8-electron mixed-valent $\left[\mathrm{Ag}_{13}\right]^{5+}$ and $\left[\mathrm{AuAg}_{12}\right]^{5+}$ core, respectively, passivated by 7 outer $\mathrm{Ag}^{+}$atoms and $12 \mathrm{dtp}$ ligands. In the $\left[\mathrm{Ag}_{20}\right]^{\prime}$ cluster the three types of metal atoms have natural atomic orbital (NAO) charges of -044 (center), +0.23 (ico., avg.) and +0.63 (cap., avg.). Thus the more favorable site for a galvanic substitution, i.e., the more electron-rich site, is, by far, the cluster center. ${ }^{27}$ This is actually what happens in $\mathbf{1}^{\prime}$, for which the three corresponding NAO metal charges are -0.68 (center), +0.25 (ico, avg.) and +0.62 (cap., avg.). Thus the effect of doping is to increase the polarity within the 13-atom core, so that gold in $\mathbf{1}^{\prime}$ can be seen as in the $\mathrm{Au}(-\mathrm{I})$ formal oxidation state. The doping increases also the HOMO-LUMO gap which goes from $1.52 \mathrm{eV}\left(\left[\mathrm{Ag}_{20}\right]^{\prime}\right)$ to $1.60 \mathrm{eV}$ (1). Since we were not able to grow single-crystals of $\mathbf{2}$ to determine its structure, we carried out calculations on 2' assuming the three structures characterized so far for $\left[\mathrm{Ag}_{21}\right]$ or [AuAg 20 ] NCs, namely of $T,{ }^{34} C_{3}{ }^{7}$ or $C_{1}^{45}$ symmetry, respectively. The three structures differ only in the configuration of their passivating shells. TD-DFT calculations ${ }^{44}$ carried out on the three structures found the best agreement of the simulated UV-vis spectra with the experimental spectrum of $\mathbf{2}$ for the $C_{1}$ structure (Figure S7 ESI ${ }^{+}$). We thus assume that 2' has the $C_{1}$ configuration. Its NAO metal charges are -0.65 (center), +0.24 (ico.) and +0.63 (cap., avg.). Clearly, the addition of an $\mathrm{Ag}^{+}$ion to $\mathbf{1}^{\prime}$ is mainly a local effect on the cluster surface. The TD-DFT simulated spectra of $\mathbf{1}^{\prime}, \mathbf{2}^{\prime}$ and $\left[\mathrm{Ag}_{20}\right]^{\prime}$ (Figure S7 ESI+) are in good agreement with their experimental counterparts. Their low-energy band is associated with a charge density shifting from the central atom to the icosahedron and to the capping $\mathrm{Ag}$ atoms. The next absorption bands have more MLCT character.

We have estimated the energy of the transformation of 1 into 2 in the presence of $\mathrm{Ag}^{+}$(Scheme 1 ) by calculating that of the model reaction $\mathbf{1}^{\prime}+\mathrm{AgCl} \rightarrow \mathbf{2}^{\prime}+\mathrm{Cl}^{-}$in THF. ${ }^{44}$ The process is found exothermic $(\Delta \mathrm{E}=-14 \mathrm{kcal} / \mathrm{mol})$, in agreement with experiment (see above). On the other hand, adding a supplementary $\mathrm{Ag}^{+}$ion to $\mathbf{2}^{\prime}$ appears unfavorable at the level of modelization.

\section{Conclusions}

In summary a new alloy $\mathrm{NC}\left[\mathrm{AuAg}_{19}\left\{\mathrm{~S}_{2} \mathrm{P}\left(\mathrm{O}^{\mathrm{n}} \mathrm{Pr}\right)_{2}\right\}_{12}\right]$ was successfully synthesized by galvanic replacement methods starting from an $\mathrm{Ag}_{20}$ template. The structural analysis has been established by single crystal $\mathrm{X}$-ray diffraction studies. We also report the transformation of $\left[\mathrm{AuAg}_{19}\left\{\mathrm{~S}_{2} \mathrm{P}\left(\mathrm{O}^{\mathrm{n}} \mathrm{Pr}\right)_{2}\right\}_{12}\right]$ into $\left[\mathrm{AuAg}_{20}\left\{\mathrm{~S}_{2} \mathrm{P}\left(\mathrm{O}^{\mathrm{n}} \mathrm{Pr}\right)_{2}\right\}_{12}\right]^{+}$via reactions with $\mathrm{Ag}^{\prime}$ salts under low temperature. Further insights into the transformation process were obtained by monitoring it with ESI-MS spectrometry and also by ${ }^{31} \mathrm{P}$ NMR spectrum. Presumably shape flexibility of the cluster envelope and structural stability associated with the doped nanocluster $\left[\mathrm{AuAg}_{20}\left\{\mathrm{~S}_{2} \mathrm{P}\left(\mathrm{O}^{\mathrm{n}} \mathrm{Pr}\right)_{2}\right\}_{12}\right]^{+}$are the key factors for this transformation. This work adds a new dimension to the 
recently established transformation chemistry of nanoclusters that involves size-structure transformations.

\section{Conflicts of interest}

"There are no conflicts to declare".

\section{Acknowledgements}

Financial support from the Ministry of Science and Technology in Taiwan (MOST 106-2113-M-259-010) is greatly acknowledged. The GENCI French national computer center is acknowledged for computational resources (grant A0010807367).

\section{Notes and references}

1 (a) R. Jin, C. Zeng, M. Zhou, and Y. Chen Chem. Rev., 2016, 116, 10346-10413. (b) R. R. Arvizo, S. Bhattacharyya, R. A Kudgus, K. Giri, R. Bhattacharya, P. Mukherjee, Chem. Soc. Rev. 2012, 41, 2943 - 2970. (c) M.-C. Daniel, D. Astruc, Chem. Rev. 2004, 104, 293-346; d) A. C. Templeton, W. P. Wuelfing, R.W. Murray, Acc. Chem. Res. 2000, 33, $27-36$.

2 (a) H. Qian, M. Zhu, Z.Wu, R. Jin, G. Li, R. Jin, Acc. Chem. Res. 2012, 45, 1470 - 1479. (b) J. F. Parker, C. A. Fields-Zinna, R. W. Murry, Acc. Chem. Res. 2010, 43, 1289 - 1296. (c) P. D. Jadzinsky, G. Calero, C. J. Ackerson, D. A. Bushnell, R. D. Kornberg, Science 2007, 318, $430-433$. (d) M.W. Heaven, A. Dass, P. S. White, K. M. Holt, R.W. Murray, J. Am. Chem. Soc. 2008, 130, 3754 - 3755. (e) M. Zhu, C. M. Aikens, F. J. Hollander, G. C. Schatz, R. Jin, J. Am. Chem. Soc. 2008, 130, 5883-5885. (f) H. Qian,W. T. Eckenhoff, Y. Zhu, T. Pintauer, R. Jin, J. Am. Chem. Soc. 2010, 132, $8280-8281$. (g) C. Zeng, H. Qian, T. Li, G. Li, N. L. Rosi, B. Yoon, R. N. Barnett, R. L. Whetten, U. Landman, R. Jin, Angew. Chem. Int. Ed. 2012, 51, 13114 - 13118. (h) C. Zeng, T. Li, A. Das, N. L. Rosi, R. Jin, J. Am. Chem. Soc. 2013, 135, 10011 - 10013. (i) X.-K. Wan, S.-F. Yuan, Z.-W. Lin, Q.-M. Wang, Angew. Chem. Int. Ed. 2014, 53, $2923-2926$.

3 (a) A. Desireddy, B. C. Conn, J. Guo, B. Yoon, R. N. Barnett, B. N. Monahan, K. Kirschbaum, W. P. Griffith, R. L. Whetten, U. Andmann, T. P. Bigioni, Nature 2013, 501, 399 - 402. (b) H. Yang, Y. Wang, H. Huang, L. Gell, L. Lehtovaara, S. Malola, H. Hakkinen, N. Zheng, Nature Commun. 2013, 4, 2422.

4 H. Yang, J. Lei, B.Wu, Y.Wang, M. Zhou, A. Xia, L. Zhenga, N. Zheng, Chem. Commun. 2013, 49, $300-302$.

5 H. Yang, Y. Wang, N. Zheng, Nanoscale 2013, 5, 2674- 2677.

6 R. S. Dhayal, Y.-R. Lin, J.-H. Liao, Y.-J. Chen, Y.-C. Liu, M.-H. Chiang, S. Kahlal, J.-Y. Saillard, C. W. Liu, Chem. Eur. J. 2016, 22, 9943 - 9947.

7 R. S. Dhayal, J.-H. Liao, Y.-C. Liu, M.-H. Chiang, S. Kahlal, J.-Y. Saillard, C. W. Liu, Angew. Chem. Int. Ed. 2015, 54, 3702 3706.

8 C. P. Joshi, M. S. Bootharaju, M. J. Alhilaly, O. M. Bakr, J. Am. Chem. Soc. 2015, 137, 11578-1158.

9 L. G. AbdulHalim, M. S. Bootharaju, Q. Tang, S. d. Gobbo, R. G. AbdulHalim, M. Eddaoudi, D.-E. Jiang, O. M. Bakr, J. Am. Chem. Soc. 2015, 137, 11970-11975.

10 D. Sun, G.-G. Luo, N. Zhang, R.-B. Huang, L.-S. Zheng, Chem. Commun. 2011, 47, $1461-1463$.

11 W. Du, S. Jin, L. Xiong, M. Chen, J. Zhang, X. Zou, Y. Pei, S. Wang, and M. Zhu J. Am. Chem. Soc. 2017, 139, 1618-1624.
12 H. Yan, Y. Wang, X. Chen, X. Zhao, L. Gu, H. Huang, J. Yan, C. Xu, G. Li, J. Wu, A. J. Edwards, B. Dittrich, Z.Tang, D. Wang, L. Lehtovaara, H. Hakkinen N. Zheng, Nature Commun. 2016, 7, 12809.

13 (a)H. Qian, D.-e. Jiang, G. Li, C. Gayathri, A. Das, R. R. Gil and R. Jin, J. Am. Chem. Soc., 2012, 134, 16159-16162. (b) S. Wang, X. Meng, A. Das, T. Li, Y. Song, T. Cao, X. Zhu, M. Zhu and R. Jin, Angew. Chem., Int. Ed., 2014, 53, 2376-2380. (c) Y. Negishi, T. Iwai and M. Ide, Chem. Commun., 2010, 46, 47134715. (d) Y. Negishi, W. Kurashige, Y. Niihori, T. Iwasa and K. Nobusada, Phys. Chem. Chem. Phys., 2010, 12, 6219. (e) Y. Niihori, W. Kurashige, M. Matsuzaki and Y. Negishi, Nanoscale, 2013, 5, 508.

14 S. Wang, Y. Song, S. Jin, X. Liu, J. Zhang, Y. Pei, X. Meng, M. Chen, P. Li and M. Zhu, J. Am. Chem. Soc., 2015, 137, 40184021.

15 K. R. Krishnadas, A. Ghosh, A. Baksi, I. Chakraborty, G. Natarajan, T. Pradeep, J. Am. Chem. Soc. 2016, 138, 140-148.

16 R. Jin and K. Nobusada, Nano Res., 2014, 7, 285-300.

17 Q. Li, S. Wang, K. Kirschbaum, K. J. Lambright, A. Das and R. Jin, Chem. Commun., 2016, 52, 5194-5197.

18 C. Yao, Y.-j. Lin, J. Yuan, L. Liao, M. Zhu, L.-h. Weng, J. Yang and Z. Wu, J. Am. Chem. Soc., 2015, 137, 15350- 15353.

19 L. Liao, S. Zhou, Y. Dai, L. Liu, C. Yao, C. Fu, J. Yang and Z. Wu, J. Am. Chem. Soc., 2015, 137, 9511-9514

20 (a) S. R. Biltek, S. Mandal, A. Sen, A. C. Reber, A. F. Pedicini, S. N. Khanna, J. Am. Chem. Soc. 2012, 135, 26-29. (b) S. R. Biltek, A. Sen, A. F. Pedicini, A. C. Reber, S. N. Khanna, J. Phys. Chem. A 2014, 118, 8314-8319.

21 S. Sarkar, I. Chakraborty, M. K. Panwar, T. Pradeep, J. Phys. Chem. Lett. 2014, 5, 3757-3762.

22 J. Y. Haifeng, H. Su, H. Yang, S. Malola, S. Lin, H. Häkkinen, N. Zheng, J. Am. Chem. Soc. 2015, 137, 11880-11883.

23 J. Yan, H. Su, H. Yang, C. Hu, S. Malola, S. Lint, B. K. Teo, H. Häkkinen, and N Zheng J. Am. Chem. Soc. 2016, 138, 1275112754.

24 Q. Li, S. Wang, K. Kirschbaum, K. J. Lambright, A. Dasa and R. Jin Chem. Commun., 2016, 52, 5194-5197.

25 C. Kumara, K. J. Gagnon, and A. Dass, J. Phys. Chem. Lett. $2015,6,1223-1228$.

26 Y. Wang, H. Su, C. Xu, G. Li, L. Gell, S. Lin, Z. Tang, H. Häkkinen, and N. Zheng, J. Am. Chem. Soc. 2015, 137, 4324-4327.

27 S. Wang, S. Jin, S. Yang, S. Chen, Y. Song, J. Zhang, M. Zhu, Sci. Adv. 2015, 1, e1500441.

28 C. Yao, J. Chen, M. Li, L. Liu, J. Yang, and Z. Wu, Nano Lett. 2015, 15, 1281-1287.

29 G. Soldan, M. A. Aljuhani, M. S. Bootharaju, L. G. AbdulHalim, M. R. Parida, A.-H. Emwas, O.F. Mohammed, O. M. Bakr, Angew. Chem., Int. Ed. 2016, 51, 5749-5753.

30 M. Zhou, J. Zhong, S. Wang, Q. Guo, M. Zhu, Y. Pei, A. Xia, J. Phys. Chem. C. 2015, 119, 18790-18797.

31 J-L. Zeng, Z-J. Guan, Y. Du, Z-A. Nan, Y-M Lin, and Q-M Wang J. Am. Chem. Soc. 2016, 138, 7848-7851.

32 (a) M. S. Bootharaju, C. P. Joshi, M. R. Parida, O. F. Mohammed, O. M. Bakr, Angew. Chem. Int. Ed. 2016, 55, 922-926. (b) M.S. Bootharaju, L. Sinatra and O. M. Bakr Nanoscale, 2016, 8, 17333-17339.

33 T. Chen, S. Yang, J. Chai, Y. Song, J. Fan, B. Rao, H. Sheng, H. Yu, M. Zhu, Sci. Adv. 2017, 3, no. 8, e1700956.

34 W-T Chang, P-Y Lee, J-H Liao, K. K. Chakrahari, S. Kahlal, Y-C Liu, M-H Chiang, J-Y Saillard, and C. W. Liu Angew. Chem. Int. Ed. 2017, 56, 10178.

35 C. Zeng, T. Li, A. Das, N. L. Rosi, R. Jin, J. Am. Chem. Soc. 2013, 135, 10011-10013.

36 C. Zeng, H. Qian, T. Li, G. Li, NL. Rosi, B. Yoon, RN. Barnett, RL. Whetten, U. Landman, Angew. Chem., Int. Ed. 2012, 51, 13114. 
37 C. Zeng, Y. Chen, K. Kirschbaum, K. Appavoo, M. Y. Sfeir, Sci. Adv. 2015, 1, e1500045.

38 (a) M. S. Bootharaju, V. M. Burlakov, T. M. D. Besong, C. P. Joshi, L. G. AbdulHalim, D. M. Black, R. L. Whetten, A. Goriely, and O. M. Bakr Chem. Mater. 2015, 27, 4289-4297. (b) M. S. Bootharaju, C. P. Joshi, L. G. AbdulHalim, J. A. Mohammad, O. M. Bakr, Chem. Mater. 2016, 28, 3292. (c) L. G. AbdulHalim, N. Kothalawala, L. Sinatra, A. Dass, O. M. Bakr, J. Am. Chem. Soc. 2014, 136, 15865.

39 X. Kang, M. Zhou, S. Wang, S. Jin, G. Sun, M. Zhu, R. Jin, Chem. Sci. 2017, 8, 2581-2587.

40 Q Li, M. G. Taylor, K. Kirschbaum, K. J. Lambright, X. Zhu, G. Mpourmpakis, R. Jin, J Colloid Interface Sci. 2017, 505, 1202.

41 Crystallographic data for 1: $\mathrm{C}_{72} \mathrm{H}_{168} \mathrm{AuAg}_{19} \mathrm{O}_{24} \mathrm{P}_{12} \mathrm{~S}_{24}$, Monoclinic, space group $\mathrm{P} 2_{1} / \mathrm{c}, \mathrm{a}=29.6903(7) \AA \mathrm{A}, \mathrm{b}=$ 17.3784(4) $\AA, c=30.3868(6) \AA, \alpha=90^{\circ}, \beta=110.3727(9)^{\circ}, \gamma=$ $90^{\circ}, V=14697.9(6) \AA^{3}, Z=4, T=150(2) \mathrm{K}, \mu=3.984 \mathrm{~mm}^{-1}$, $\mathrm{R}_{\text {int }}=0.0273, \mathrm{R} 1=0.0426, \mathrm{WR} 2=0.1012[\mathrm{I}>2 \sigma(\mathrm{I})]$. The goodness of fit on $\mathrm{F}^{2}$ was 1.033 .

42 J. Radnik, C. Mohrb, P. Claus, Phys. Chem. Chem. Phys., 2003, 5, 172-177.

43 M. Zhou, J. Zhong, S. Wang, Q. Guo, M. Zhu,Y. Pei, and A. Xia J. Phys. Chem. C 2015, 119, 18790-1879.

44 DFT and TDDFT calculations were carried out at the BP86/Def2TZVP and CAM-B3LYP/Def2TZVP levels, respectively (see supplementary informations).

45 Liao, J.-H.; Kahlal, S.; Liu, Y.-C.; Chiang, M.-H.; Saillard, J.-Y.; Liu, C. W. J. Cluster Sci. submitted. 